Family Profile No. 22, 2021

\title{
Variation in Stepfamilies among Currently Cohabiting and Married Men and Women Under 50
} Author: Karen Benjamin Guzzo

Among women, an increasing proportion of current unions are stepfamilies-unions in which one or both partners had children from a prior relationship (FP-21-21). In this profile, we consider how the share of men's and women's coresidential unions that are stepfamilies varies by union type and marital history, educational attainment, and race/ethnicity. We examine men and women under age 50 who are currently living with a partner (married or cohabiting) using data from the 2015-2019 cycles of the National Survey of Family Growth (NSFG), which represent the year 2017 when weighted.

- Overall, the share of women's unions that are stepfamilies (35\%) was higher than the share among men (25\%), not shown.

- This holds true regardless of union type and marital history, educational attainment, or race/ethnicity.

Variation across Union Type and Marital History, by Gender

- For union type and marital history, the absolute gender gap was largest for those in a higher-order marriage, with $54 \%$ of men in a $2^{\text {nd }}$ or later marriage in a stepfamily compared to $83 \%$ of women - a difference of 29 percentage points.

- Stepfamilies were least common among $1^{\text {st }}$ marriages and most common among previously married cohabiting men and women.

- Among never married cohabiting men and women, $33 \%$ and $41 \%$, respectively, were in stepfamilies.

- Partnered women with a previous marriage had high shares living in a stepfamily, at $83 \%$ of those in a remarriage and $87 \%$ of those in a cohabitation.

Variation across Education, by Gender

Figure 2. Stepfamily Share of Unions, by Education and Gender

Men Women

Less than HS

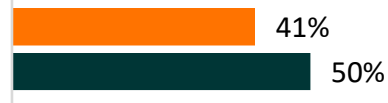

HS/GED/Some college

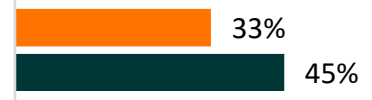

AA degree

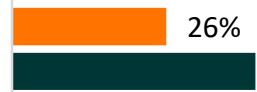

$41 \%$

BA degree or more

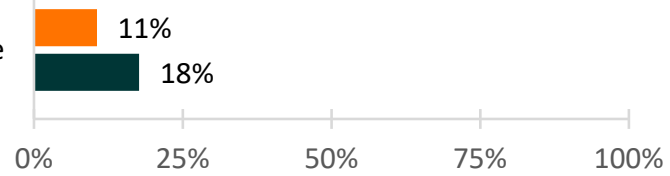

Figure 1. Stepfamily Share of Unions, by Union Type and Gender Men $\square$ Women

1st marriage

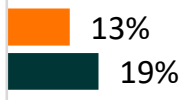

Higher-order marriage

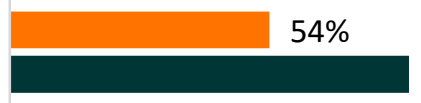

$83 \%$

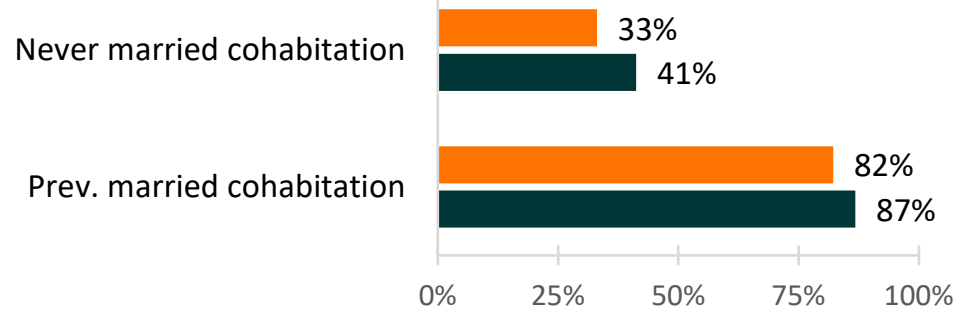

Source: NCFMR analyses of the 2015-2019 NSFG, weighted to represent 2017

- Across education levels, the absolute gender gap in stepfamilies was largest among those with an associate degree - among partnered men, $26 \%$ were living in stepfamilies compared to $41 \%$ among women.

- Of unions among those without a high school degree, four in ten were stepfamilies for men and one half were stepfamilies for women.

- Less than one fifth of currently cohabiting or married men and women with a college degree or more were in a stepfamily, at $11 \%$ and $18 \%$ respectively.

Source: NCFMR analyses of the 2015-2019 NSFG, weighted to represent 2017. 


\section{Variation across Race-Ethnicity, by Gender}

- The absolute gender gap varied little by race-ethnicity, with the share of cohabiting and married women in a stepfamily about 10 percentage points higher than their male counterparts across groups.

- The share of stepfamily unions across race-ethnicity and gender was highest for Black women, at $56 \%$, and lowest for 'Other' race men, at $18 \%$.

- Stepfamily prevalence by gender was similar among Whites and Hispanics - about one fourth of men and about one third of women were in a stepfamily.

- Less than one fifth of 'Other' race men in a union were in a stepfamily compared to just over one fourth of 'Other' race women.

Figure 3. Stepfamily Share of Unions, by Race-Ethnicity and Gender

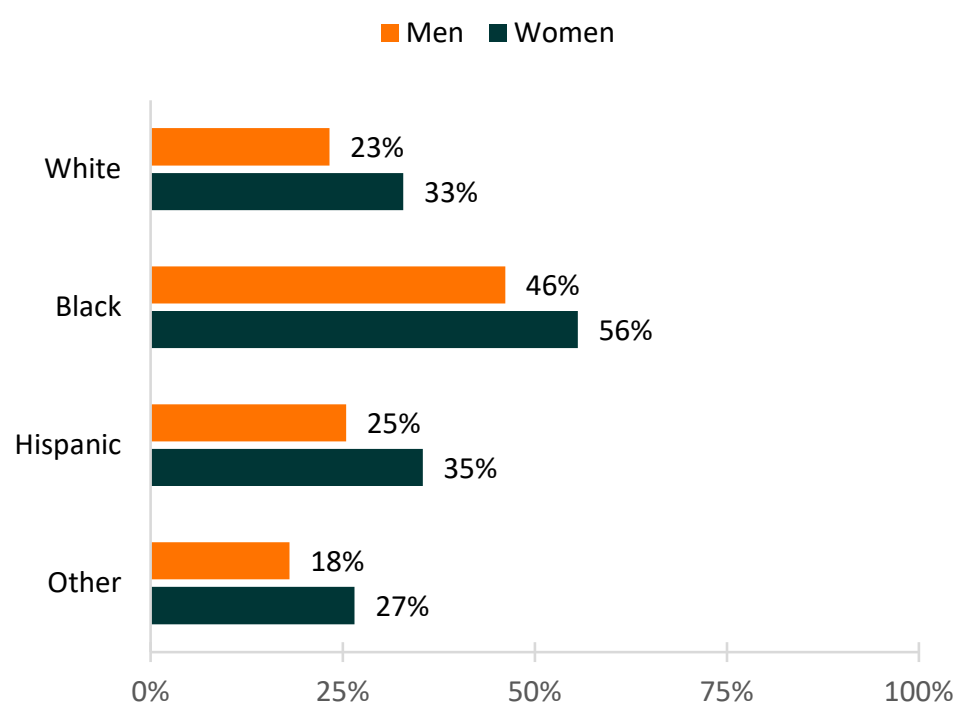

Source: NCFMR analyses of the 2015-2019 NSFG, weighted to represent 2017.

\section{Overall, the share of women's unions that are stepfamilies (35\%) was higher than the share among men (25\%).}

Data Sources:

National Center for Health Statistics (NCHS). National Survey of Family Growth Public-Use Data and Documentation. Hyattsville, MD: CDC National Center for Health Statistics. https://www.cdc.gov/nchs/nsfg/index.htm

\section{References:}

Guzzo, K. B. (2021). Stepfamilies among currently cohabiting and married women under 45, 1988 and 2017. Family Profiles, FP-21-21. Bowling Green, OH: National Center for Family \& Marriage Research. https://doi.org/10.25035/ncfmr/fp-21-21

\section{Suggested Citation:}

Guzzo, K. B. (2021). Variation in stepfamilies among currently cohabiting and married men and women under 50. Family Profiles, FP-21-22. Bowling Green, OH: National Center for Family \& Marriage Research. https://doi.org/10.25035/ncfmr/fp-21-22 